Brief communication

\title{
Alterations in the Balance of Amyloid- $\beta$ Protein Precursor Species in the Cerebrospinal Fluid of Alzheimer's Disease Patients
}

Lopez-Font I, Boix CP, Zetterberg H, Blennow K, Sáez-Valero J

*To whom correspondence should be addressed: Instituto de Neurociencias de Alicante, Universidad Miguel Hernández-CSIC, Av. Ramón y Cajal s/n, Sant Joan d'Alacant, E-03550, Spain. j.saez@umh.es. Tel.:+34 965919580, Fax:+34 965919561. 


\begin{abstract}
This study assesses whether C-terminal fragments (CTF) of the amyloid precursor protein (APP) are present in cerebrospinal fluid (CSF) and their potential as biomarkers for Alzheimer's disease (AD). We demonstrate that APP-CTFs are detectable in human $\mathrm{CSF}$, the most abundant being a $25-\mathrm{kDa}$ fragment, probably resulting from proteolytic processing by $\eta$-secretase. The CSF level of this $25-\mathrm{kDa}$ CTF is higher in subjects with autosomal dominant AD patients linked to PSEN1 mutations, in demented Down syndrome individuals and in sporadic AD subjects compared to age-matched controls. Our data suggest that APP-CTF could be a potential diagnostic biomarker for AD.
\end{abstract}




\section{Background}

Accumulation of the $\beta$-amyloid peptide $(\mathrm{A} \beta)$ in the brain is an early and specific phenomenon associated with the pathogenesis of Alzheimer's disease (AD) (Scheltens et al., 2016). Many reports support that the determination of $A \beta 42$ in cerebrospinal fluid (CSF) is a core biomarker for AD (Blennow et al., 2015). While the amount of the pathological species of $A \beta$ is increased in the AD brain, their levels in CSF are decreased, probably due to increased brain deposition. To enable monitoring early disturbance in amyloid precursor protein (APP) and A $\beta$ mis-metabolism additional biomarkers are needed.

Other plausible biomarkers for $\mathrm{AD}$ are additional fragments resulting from the processing of the amyloid precursor protein (APP), which may contribute to A $\beta$ deposition in the AD brain. APP is a large type I transmembrane spanning protein consisting of a large N-terminal extracellular domain, a hydrophobic transmembrane domain, and a short intracellular C-terminal domain. APP is usually cleaved by $\alpha$ secretase (ADAM10; leading to non-amyloidogenic pathway), or by $\beta$-secretase (BACE1; leading to amyloidogenic pathway), which causes the secretion of large sAPP $\alpha$ and sAPP $\beta$ N-terminal fragments (NTFs). CSF levels of sAPP $\alpha$ and sAPP $\beta$ show no change in $\mathrm{AD}$ (Olsson et al., 2016). The membrane remaining C-terminal fragments (CTFs) are always processed by $\gamma$-secretase generating shortest intracellular domain (AICD) peptides (for a review see Haass et al., 2012).

APP can also undergo alternative proteolytic processing pathways (see recent review Andrew et al., 2016). Thereby, concerted cleavage of $\beta$-secretase and $\alpha$-secretase result in the secretion of sAPP $\beta$ and shorter A $\beta$ peptides (Portelius et al., 2011). The presence in CSF of short NTF derivatives of APP, which generation does not involve $\alpha$ secretase or BACE, has been also demonstrated (Portelius et al., 2010). More 
interestingly in the context of this report, a recently discovered alternative physiological APP processing pathway driven by an asparagine endopeptidase named $\delta$-secretase (Zang et al., 2015) or by a metalloproteinase named $\eta$-secretase (Willen et al., 2015) will generate alternative proteolytic metabolites, including NTFs and CTFs, of different molecular mass.

In addition to the different species of $\mathrm{A} \beta$, all the large extracellular APP-NTFs have been studied in human CSF (Palmert et al., 1989; Ghiso et al., 1989; Willen et al., 2015); but the presence of APP-CTFs in CSF has not been reported to date. In this study we investigated if APP-CTFs are detectable in CSF, characterized the major APP-CTF immunoreactive band, and determined whether the levels of this peptide fragment are altered in autosomal dominant AD (ADAD), Down syndrome subjects with Alzheimer's type dementia (dDS), and sporadic AD subjects (sAD). 


\section{Material and methods}

\section{Patients}

Lumbar CSF samples were obtained from ADAD subjects that were all carriers of PSEN1 mutations and who were part of the Genetic Counseling Program for familiar dementia (PICOGEN) at the Hospital Clínic (Barcelona, Spain). This group included 7 subjects carrying PSEN1 mutations, and 7 age-matched non-mutation carriers from the same families (non-disease controls: NC). We also included lumbar CSF samples from 7 dDS subjects, along with 7 age-matched NC obtained from the Hospital Sant Pau (Barcelona, Spain). In addition, 20 patients with sAD defined as patients with cognitive symptoms and a CSF biomarker profile indicating AD (high total tau and phosphorylated tau together with low A $\beta 42$ levels; see Supplemental Table 1) and 20 age-matched controls defined as (patients with non-specific symptoms without neurochemical evidence of AD) were also obtained from the Clinical Neurochemistry Laboratory (Mölndal, Sweden). All AD patients fulfilled the 2011 NIA-AA criteria for dementia (McKann et al., 2011).

\section{Western blotting and immunoprecipitation}

Samples of CSF $(30 \mu \mathrm{L})$ were denatured at $98^{\circ} \mathrm{C}$ for 5 min and were resolved by electrophoresis on $16.5 \%$ Tris-Tricine gels. Following electrophoresis, proteins were blotted onto nitrocellulose membranes (Schleicher \& Schuell Bioscience, GmbH). CTFs of APP were detected using the following anti-APP C-terminal antibodies: C1/6.1 (mouse monoclonal; Covance), A8717 (rabbit polyclonal; Sigma), and Y188 (rabbit monoclonal; Abcam), as well as with the rat antibodies 2D8 and 2E9 (Willem et al., 2015). To assess the specificity of the immunoreactive bands, samples were resolved by simultaneous detection of immunoreactivity to two antibodies. Blots were then probed 
with the appropriate conjugated secondary antibodies and imaged on an Odyssey $\mathrm{Clx}$ Infrared Imaging System (LI-COR). Band intensities were analyzed using LI-COR software (Image Studio Lite). A control CSF sample was used to normalize the immunoreactive signal between blots.

For immunoprecipitation, samples were precleared for $2 \mathrm{~h}$ at $4{ }^{\circ} \mathrm{C}$ by incubation with protein A-Sepharose (Sigma-Aldrich). Immunoprecipitations were performed at $4^{\circ} \mathrm{C}$ by incubating $150 \mu \mathrm{L}$ of CSF, overnight with the indicated anti-APP antibody previously coupled to protein A-Sepharose using dimethyl pimelimidate dihydrochloride (Sigma-Aldrich Co). Precipitated proteins were washed with PBS and eluted with $0.1 \mathrm{M}$ glycine buffer at $\mathrm{pH} 2.5$. After $\mathrm{pH}$ neutralization, supernatants were denatured in Laemmli sample buffer at $98^{\circ} \mathrm{C}$ for $5 \mathrm{~min}$ and subjected to SDS-PAGE. The membranes were then probed with an alternative anti-APP antibody.

\section{Measurement of T-tau, P-tau and A $\beta 42$ by ELISA}

Total tau (T-tau), phosphorylated tau (P-tau) and A $\beta 1-42(\mathrm{~A} \beta 42)$ concentrations in CSF were measured using INNOTEST ELISA methods (Fujirebio Europe).

\section{Statistical analysis}

All data were analyzed using SigmaStat (Version 3.5; Systac Software Inc.) by Student's $t$ test (two-tailed) for determination of exact $p$ values. Correlation was assessed by linear regression. Results are presented as means \pm SEM. 


\section{Results}

\section{APP-CTFs are present in human CSF}

To determine the presence of APP-CTFs in human CSF, we first examined human CSF samples by Western blotting using three different anti-CTF antibodies (a schematic representation of APP and epitopes for antibodies is represented in Fig. 1A). Immunoblotting revealed a similar pattern of immunoreactive bands, with a predominant band of $\sim 25 \mathrm{kDa}$ (Fig. 1B). This band was also observed with the 2D8 and 2E9 antibodies, both against an extracellular domain close to the transmembrane

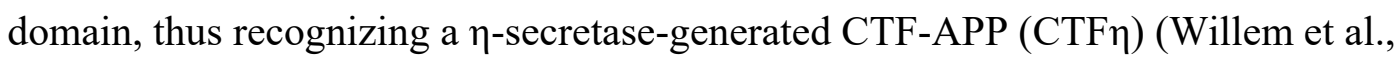
2015). Simultaneous assay of combined fluorescence with the A8717 and 2E9 antibodies indicated that the major $25 \mathrm{kDa}$ band is compatible with the CTF ; similar co-labelling was revealed with antibodies C1/6.1 and 2D8 (Supplemental Fig. 1). To further examine the identity of CTF bands in human CSF, we performed immunoprecipitation/Western blot analysis (Fig. 1C). CSF samples were immunoprecipitated using the A8717 antibody and blotted with the Y1887 antibody, confirming the identity of the $25-\mathrm{kDa}$ band as an APP-CTF. Immunoprecipitating with 2D8 antibody and blotting with A8717 antibody confirmed the 25-kDa band as a CTF .

\section{The 25-kDa CTF $\eta$ is increased in AD CSF}

To assess whether APP-CTF levels are altered in AD, we first analyzed CSF samples from genetically determined AD subjects. The $25-\mathrm{kDa}$ band was detected with A8717 antibody in all CSF analyzed (Fig. 2A). The level of the 25-kDa APP-CTF band in the CSF from ADAD subjects increased $(95 \pm 27 \% ; p=0.01)$ compared to those in agematched NC composed by non-mutation carriers from the same families (Fig. 2A). DS is also considered a pre-symptomatic AD (Dubois et al., 2014). Once more, an increase 
$(68 \pm 18 \% ; p=0.01)$ in the level of the $25-\mathrm{kDa}$ APP-CTF band was determined in CSF samples from dDS patients, comparing these to age-matched NC (Fig. 2B). Finally, we found that the immunoreactivity for this band increases $(35 \pm 9 \%$; $=0.01)$ in $\mathrm{SAD}$ compared to age-matched NC subjects (Fig. 2C). CSF samples from SAD subjects also showed similar increases for the 25-kDa band when analyzed with the 2D8 antibody $(35 \pm 9 \% ; p=0.01)$, correlating tightly the estimation of the levels calculated with the A8717 antibody (Supplemental Fig. 2).

\section{Discussion}

Here, we demonstrate that APP-CTFs are detectable in human CSF. Particularly, the most abundant soluble APP-CTF is attributable to $25-\mathrm{kDa}$ CTF recently characterize as the result of proteolytic processing by $\eta$-secretase (Willem et al., 2015). Canonical APP proteolysis occurs via $\alpha$ - and $\beta$-secretases, resulting in $\mathrm{CTF} \alpha$ and $\mathrm{CTF} \beta$ with a molecular mass lower than $15 \mathrm{kDa}$; but novel APP-CTF that migrate $\sim 25 \mathrm{kDa}$ have been described (Wang et al., 2015). As an intermediate of proteolytic process, the presence of any APP-CTF in CSF was unexpected. Anyhow, the presence in CSF of soluble forms of full-length membrane proteins containing the transmembrane and intracellular domains is not an unusual finding (Lopez-Font et al., 2015). The mechanisms by which these membrane-bound proteins reached the CSF are unknown, but neuronal death may be a major contributing factor.

Different APP C-terminal antibodies confirmed the $25 \mathrm{kDa}$ CTF $\eta$ as the predominant band in human CSF. As stated, these APP proteolytic fragments are derived from a constitutive processing step driven by a $\eta$-secretase that is partially in dynamic equilibrium with $\alpha$ - and $\beta$-secretase-mediated proteolysis (Haass et al., 1992; Willem et al., 2015; Lauritzen et al., 2016). The current canonical views about APPrelated cleavage events are likely a partial understanding of the overall process. How 
secretases compete for the APP substrate and whether subcellular compartmentalization of APP and secretases is responsible of the dynamic equilibrium between secretases is under discussion (Gandhi et al., 2004). Thus, one may speculate that the particular abundance of the 25-kDa CTF $\eta$ in CSF is related with compartmentalization of secretases, resulting in prolonged time of residence of these CTF $\eta$ in comparison with canonical CTF $\alpha$ and CTF $\beta$. Anyhow, the other fragments derived of the further

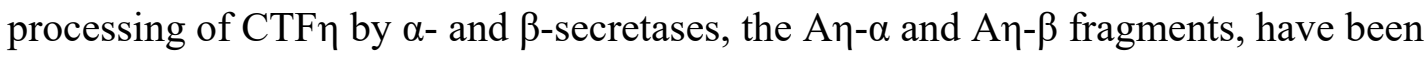
also identified in human CSF with levels similar than those for A $\beta$ (Willem et al., 2015).

Our determination of the CTFn-CTF levels by Western blotting displayed large overlap for $\mathrm{SAD}$, whereas superior discrimination was obtained for ADAD and $\mathrm{ADS}$ subjects. Interestingly, APP CTF $\beta$ levels are also in frontal cortex brain homogenates obtained from patients (Pera et al., 2013). Further studies will indicate if distinct pattern of APP processing in ADAD and SAD affect the generation of different APP-CTFs. In our study all the pathological groups were compared with age-matched controls obtained from the same center of sample collection. The possibility that APP-CTF levels varies with age should be considered and deserve a specific study with larger number of samples. In any case, it will be valuable to replicate these finding using techniques such as ELISA, to evaluate their true potential as biomarkers. However, this desirable outcome will be challenging. We have described that the soluble full-length APP, containing the $\mathrm{C}$-terminal domain, also exists in CSF as heteromeric complexes compromising other sAPP species (Cuchillo-Ibañez et al., 2015), and transmembrane domain, as well intracellular C-terminal domain could participate in APP dimerization (discussed in Isbert et al., 2012). Thus, future studies should develop custom panspecific antibodies targeting the predicted N-terminal sequence of the APP-CTFs present in CSF for preventing co-precipitation of other APP fragment. Anyhow, even 
the disadvantages of Western blotting for quantitative analysis, we considered that based on the data present in this study, there are sufficient evidence to justify further studies on the determination of APP-CTFs as a potential diagnostic biomarker of AD.

\section{Acknowledgments}

We thank Drs C. Haass and M. Willem (Biomedical Center, Ludwig-MaximiliansUniversity Munich, Munich, Germany) for the generous gift of the 2D8 and 2E9 antibodies. This study was funded in part by the EU BIOMARKAPD-Joint Programming on Neurodegenerative Diseases (JPND) project, by the Instituto de Salud Carlos III (ISCIII grants PI11/03026 to JSV, PI11/02425 and PI14/01126 to JF, PI11/03035 and PI14/1561 to AL, PI08/0036 and PI12/00013 to RSV, and PI11/03023 to JLM), co-financed by the Fondo Europeo de Desarrollo Regional, under the aegis of JPND, and through CIBERNED, ISCIII. This work was also supported by the Fundació Catalana de Síndrome de Down and by a "Marató TV3" grant (20141210 to JF) and a grant from the Griffols Foundation, and the Torsten Söderberg Foundation, Sweden (to $\mathrm{KB})$.

\section{Competing interests}

The authors have no competing interests to disclose in connection with this article. 


\section{References}

Andrew RJ, Kellett KA, Thinakaran G, Hooper NM. A Greek Tragedy: the Growing Complexity of Alzheimer Amyloid Precursor Protein Proteolysis. J Biol Chem. 2016 Jul 29.

Blennow K, Mattsson N, Schöll M, Hansson O, Zetterberg H. Amyloid biomarkers in Alzheimer's disease. Trends Pharmacol Sci. 2015 May;36(5):297-309.

Cuchillo-Ibañez I, Lopez-Font I, Boix-Amorós A, Brinkmalm G, Blennow K, Molinuevo JL, Sáez-Valero J. Heteromers of amyloid precursor protein in cerebrospinal fluid. Mol Neurodegener. 2015 Jan 8;10:2.

Dubois B, Feldman HH, Jacova C, Hampel H, Molinuevo JL, Blennow K, DeKosky ST, Gauthier S, Selkoe D, Bateman R, Cappa S, Crutch S, Engelborghs S, Frisoni GB, Fox NC, Galasko D, Habert MO, Jicha GA, Nordberg A, Pasquier F, Rabinovici G, Robert P, Rowe C, Salloway S, Sarazin M, Epelbaum S, de Souza LC, Vellas B, Visser PJ, Schneider L, Stern Y, Scheltens P, Cummings JL. Advancing research diagnostic criteria for Alzheimer's disease: the IWG-2 criteria. Lancet Neurol 2014; 13:614-629.

Gandhi S, Refolo LM, Sambamurti K. Amyloid precursor protein compartmentalization restricts beta-amyloid production: therapeutic targets based on BACE compartmentalization. J Mol Neurosci. 2004;24(1):137-43.

Ghiso J, Tagliavini F, Timmers WF, Frangione B: Alzheimer's disease amyloid precursor protein is present in senile plaques and cerebrospinal fluid: immunohistochemical and biochemical characterization. Biochem Biophys Res Commun 1989, 163:430-437.

Haass C, Koo EH, Mellon A, Hung AY, Selkoe DJ. Targeting of cell-surface betaamyloid precursor protein to lysosomes: alternative processing into amyloid-bearing fragments. Nature. 1992 Jun 11;357(6378):500-3. 
Haass C, Kaether C, Thinakaran G, Sisodia S. Trafficking and proteolytic processing of APP. Cold Spring Harb Perspect Med. 2012 May;2(5):a006270.

Isbert S, Wagner K, Eggert S, Schweitzer A, Multhaup G, Weggen S, Kins S, Pietrzik CU. APP dimer formation is initiated in the endoplasmic reticulum and differs between APP isoforms. Cell Mol Life Sci. 2012 Apr;69(8):1353-75.

Jansen WJ, Ossenkoppele R, Knol DL, Tijms BM, Scheltens P, Verhey FR, Visser PJ; Amyloid Biomarker Study Group, Aalten P, Aarsland D, Alcolea D, Alexander M, Almdahl IS, Arnold SE, Baldeiras I, Barthel H, van Berckel BN, Bibeau K, Blennow K, Brooks DJ, van Buchem MA, Camus V, Cavedo E, Chen K, Chetelat G, Cohen AD, Drzezga A, Engelborghs S, Fagan AM, Fladby T, Fleisher AS, van der Flier WM, Ford L, Förster S, Fortea J, Foskett N, Frederiksen KS, Freund-Levi Y, Frisoni GB, Froelich L, Gabryelewicz T, Gill KD, Gkatzima O, Gómez-Tortosa E, Gordon MF, Grimmer T, Hampel H, Hausner L, Hellwig S, Herukka SK, Hildebrandt H, Ishihara L, Ivanoiu A, Jagust WJ, Johannsen P, Kandimalla R, Kapaki E, Klimkowicz-Mrowiec A, Klunk WE, Köhler S, Koglin N, Kornhuber J, Kramberger MG, Van Laere K, Landau SM, Lee DY, de Leon M, Lisetti V, Lleó A, Madsen K, Maier W, Marcusson J, Mattsson N, de Mendonça A, Meulenbroek O, Meyer PT, Mintun MA, Mok V, Molinuevo JL, Møllergård HM, Morris JC, Mroczko B, Van der Mussele S, Na DL, Newberg A, Nordberg A, Nordlund A, Novak GP, Paraskevas GP, Parnetti L, Perera G, Peters O, Popp J, Prabhakar S, Rabinovici GD, Ramakers IH, Rami L, Resende de Oliveira C, Rinne JO, Rodrigue KM, Rodríguez-Rodríguez E, Roe CM, Rot U, Rowe CC, Rüther E, Sabri O, Sanchez-Juan P, Santana I, Sarazin M, Schröder J, Schütte C, Seo SW, Soetewey F, Soininen H, Spiru L, Struyfs H, Teunissen CE, Tsolaki M, Vandenberghe R, Verbeek MM, Villemagne VL, Vos SJ, van Waalwijk van Doorn LJ, Waldemar G, Wallin A, Wallin ÅK, Wiltfang J, Wolk DA, Zboch M, Zetterberg H. Prevalence of 
cerebral amyloid pathology in persons without dementia: a meta-analysis. JAMA. 2015 May 19;313(19):1924-38.

Lauritzen I, Pardossi-Piquard R, Bourgeois A, Pagnotta S, Biferi MG, Barkats M, Lacor P, Klein W, Bauer C, Checler F. Intraneuronal aggregation of the $\beta$-CTF fragment of APP (C99) induces A $\beta$-independent lysosomal-autophagic pathology. Acta Neuropathol. 2016 Aug;132(2):257-76.

Lopez-Font I, Cuchillo-Ibañez I, Sogorb-Esteve A, García-Ayllón MS, Sáez-Valero J. Transmembrane Amyloid-Related Proteins in CSF as Potential Biomarkers for Alzheimer's Disease. Front Neurol. 2015 Jun 2;6:125.

McKhann GM, Knopman DS, Chertkow H, Hyman BT, Jack CR Jr, Kawas CH, Klunk WE, Koroshetz WJ, Manly JJ, Mayeux R, Mohs RC, Morris JC, Rossor MN, Scheltens P, Carrillo MC, Thies B, Weintraub S, Phelps CH. The diagnosis of dementia due to Alzheimer's disease: recommendations from the National Institute on AgingAlzheimer's Association workgroups on diagnostic guidelines for Alzheimer's disease. Alzheimers Dement. 2011 May;7(3):263-9.

Olsson B, Lautner R, Andreasson U, Öhrfelt A, Portelius E, Bjerke M, Hölttä M, Rosén C Olsson C, Strobel G, Wu E, Dakin K, Petzold M, Blennow K, Zetterberg H. CSF and blood biomarkers for Alzheimer's disease: a systematic review and metaanalysis. Lancet Neurol 2016;15:673-684.

Palmert MR, Siedlak SL, Podlisny MB, Greenberg B, Shelton ER, Chan HW, Usiak M, Selkoe DJ, Perry G, Younkin SG: The beta-amyloid protein precursor of Alzheimer disease has soluble derivatives found in human brain and cerebrospinal fluid. Proc Natl Acad Sci USA 1989, 86:6338-6342.

Pera M, Alcolea D, Sánchez-Valle R, Guardia-Laguarta C, Colom-Cadena M, Badiola N, Suárez-Calvet M, Lladó A, Barrera-Ocampo AA, Sepulveda-Falla D, Blesa R, Molinuevo JL, Clarimón J, Ferrer I, Gelpi E, Lleó A. Distinct patterns of APP 
processing in the CNS in autosomal-dominant and sporadic Alzheimer disease. Acta Neuropathol. 2013 Feb;125(2):201-13

Portelius E, Price E, Brinkmalm G, Stiteler M, Olsson M, Persson R, WestmanBrinkmalm A, Zetterberg H, Simon AJ, Blennow K: A novel pathway for amyloid precursor protein processing. Neurobiol Aging 2011, 32:1090-1098.

Portelius E, Brinkmalm G, Tran A, Andreasson U, Zetterberg H, WestmanBrinkmalm A, Blennow K, Ohrfelt A. Identification of novel N-terminal fragments of amyloid precursor protein in cerebrospinal fluid. Exp Neurol. 2010 Jun;223(2):351-8

Scheltens P, Blennow K, Breteler MM, De Strooper B, Frisoni GB, Salloway S, Van der Flier WM. Alzheimer's disease. Lancet 2016;388:505-517.

Zetterberg H., Blennow K., Hanse E. Amyloid beta and APP as biomarkers for Alzheimer's disease. Exp Gerontol, 45 (2010), pp. 23-29.

Zhang Z, Song M, Liu X, Su Kang S, Duong DM, Seyfried NT, Cao X, Cheng L, Sun YE, Ping Yu S, Jia J, Levey AI, Ye K. Delta-secretase cleaves amyloid precursor protein and regulates the pathogenesis in Alzheimer's disease. Nat Commun. 2015 Nov $9 ; 6: 8762$.

Wang H, Sang N, Zhang C, Raghupathi R, Tanzi RE, Saunders A. Cathepsin L Mediates the Degradation of Novel APP C-Terminal Fragments. Biochemistry. 2015 May 12;54(18):2806-16.

Willem M, Tahirovic S, Busche MA, Ovsepian SV, Chafai M, Kootar S, Hornburg D, Evans LD, Moore S, Daria A, Hampel H, Müller V, Giudici C, Nuscher B, Wenninger-Weinzierl A, Kremmer E, Heneka MT, Thal DR, Giedraitis V, Lannfelt L, Müller U, Livesey FJ, Meissner F, Herms J, Konnerth A, Marie H, Haass C. ๆ-Secretase processing of APP inhibits neuronal activity in the hippocampus. Nature. 2015 Oct $15 ; 526(7573): 443-7$. 


\section{Figure Legends}

Figure 1. Soluble CTFs of APP are present in human CSF. (A) Schematic representation of full-length APP processing by secretases. The epitopes for the antibodies used in this study are indicated. (B) Western blotting of three human CSF samples from non-demented controls subjects, resolved with the indicated antibody. 2D8 and 2E9 also detect other soluble fragments around $\sim 15 \mathrm{kDa}$, termed $\mathrm{A \eta}$, generated after concerted cleavage by $\eta$-secretase and $\alpha / \beta$-secretases (see Willem et al., 2015). 2D8 antibody also detects A $\beta$ monomers. (C) CSF aliquots (Total, T) were immunoprecipitated with the indicated antibody and precipitated proteins (bound fraction, IP) were immunoblotted with the indicated alternative antibody. In the absence of capture-antibody (IPc), no bands were observed.

\section{Figure 2. Higher levels of the 25-kDa APP-CTF band in the CSF of AD subjects.}

(A) Representative blot of the APP-CTF in the CSF samples from 7 symptomatic ADAD and 7 age-matched $\mathrm{NC}$, which were from the same families that ADAD subjects but that did not carry mutations (black symbol; see also Table 1). Densitometric quantification of the immunoreactivity from the $25-\mathrm{kDa}$ band is also shown. (B) Representative blot and densitometric quantification in CSF from 7 DS subjects with dementia of the Alzheimer's type (dDS) and 7 age-matched NC. (C) Representative blot and densitometric quantification of the immunoreactivity from the 25-KDa APP-CTF in CSF samples from $20 \mathrm{sAD}$ and 20 age-matched NC subjects. Immunodetection was performed with the A8717 antibody. $p$ values are displayed. 
Supplemental Figure 1. SDS-PAGE analysis and fluorescence detection of soluble CTFs of APP in human CSF. To probe that the 25-kDa specie resolved with different antibodies is the same, three aliquots of CSF were analyzed by SDS-PAGE and resolved with (A) A8717 and 2E9 antibodies, or (B) C1/6.1 and 2D8 antibodies, simultaneously. The fluorescence of the secondary antibodies was detected with the Odyssey CLx Infrared Imaging system (LI-COR).

Supplemental Figure 2. Corroboration of the increase in the 25-kDa APP-CTF in the CSF of SAD subjects. Representative blot and densitometric quantification of the 25-kDa APP-CTF in the CSF samples from 20 probable sAD 20 age-matched NC subjects blotted with the A8717 antibody (same data that in Fig. 2) and with the 2D8 antibody. A positive correlation was obtained when immunoreactive levels estimated with both antibodies from the same subjects were confronted. Regression linear coefficient (R) and $p$ values are displayed. 
Table 1: Clinical, demographic data and classic CSF biomarker levels.

\begin{tabular}{|c|c|c|c|c|c|}
\hline Group & $\begin{array}{c}\text { Age } \\
\text { (years) }\end{array}$ & Gender & $\begin{array}{c}\text { CSF Aß42 } \\
\text { (pg/mL) }\end{array}$ & $\begin{array}{c}\text { CSF T-tau } \\
\text { (pg/mL) }\end{array}$ & $\begin{array}{c}\text { CSF P-tau } \\
\text { (pg/mL) }\end{array}$ \\
\hline sAD & $71 \pm 2[55-86]$ & $15 \mathrm{~F} / 5 \mathrm{M}$ & $412 \pm 19 * *$ & $665 \pm 52 * *$ & $84 \pm 6 * *$ \\
\hline $\mathrm{NC}$ & $72 \pm 2[57-88]$ & $6 \mathrm{~F} / 14 \mathrm{M}$ & $739 \pm 32$ & $233 \pm 14$ & $36 \pm 2$ \\
\hline ADAD & $43 \pm 2$ [31-49] & $5 \mathrm{~F} / 2 \mathrm{M}$ & $266 \pm 49 * *$ & $883 \pm 204 * *$ & $168 \pm 69^{*}$ \\
\hline $\mathrm{NC}$ & $39 \pm 3[25-47]$ & $5 \mathrm{~F} / 2 \mathrm{M}$ & $809 \pm 94$ & $245 \pm 29$ & $46 \pm 4$ \\
\hline $\mathrm{dDS}$ & $53 \pm 2[43-57]$ & $4 \mathrm{~F} / 3 \mathrm{M}$ & $422 \pm 17 *$ & $767 \pm 170^{*}$ & $108 \pm 19^{*}$ \\
\hline $\mathrm{NC}$ & $48 \pm 2[47-53]$ & $5 \mathrm{~F} / 2 \mathrm{M}$ & $751 \pm 84^{*}$ & $160 \pm 26$ & $33 \pm 5$ \\
\hline
\end{tabular}

The PSEN1 mutations included in this study from ADAD cases (autosomal dominant AD subjects) corresponded to 3 carriers of L286P, and one S169P, L173F, L235R and L282R. The data represent the means \pm SEM, and for age the range of values is also indicated. All the pathological groups were compared with age-matched $\mathrm{NC}$ obtained from the same Hospital. Significantly different $* * p<0.005 ;{ }^{*} p<0.05$ from the NC group. This study was approved by the ethics committee at the Miguel Hernandez University and it was carried out in accordance with the Declaration of Helsinki. 